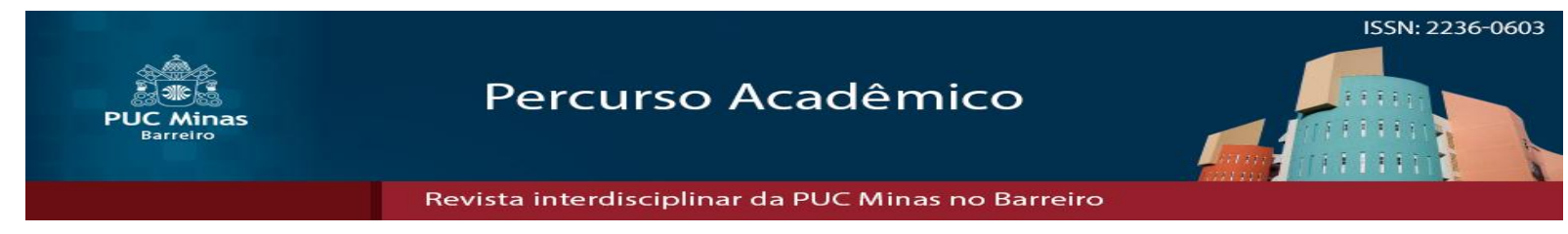

\title{
Desenvolvendo o Index para Inclusão no contexto brasileiro: experiências de reflexão/ação sobre processos de inclusão e exclusão em Educação
}

\author{
Developing the Index for Inclusion in the Brazilian context: \\ experiences of reflection/action about inclusion and exclusion \\ processes in Education
}

\author{
Mônica Pereira dos Santos ${ }^{1}$ \\ Manoella Rodrigues Pereira Senna Vasconcelos da Silva ${ }^{2}$ \\ Regina Maria de Souza Correia Pinto ${ }^{3}$ \\ Carolina Barreiros de $\mathrm{Lima}^{4}$
}

Resumo

O presente artigo tem por objetivo relatar experiências de pesquisa acerca do uso do Index para Inclusão no contexto brasileiro e sua contribuição para os estudos sobre processos de inclusão e exclusão em Educação. Inicialmente apresentamos o instrumento e seus objetivos. Em seguida, compartilhamos as experiências de pesquisa que envolvem seu uso no país. Desde sua construção e publicação na Inglaterra por Booth; Ainscow (2000), foi traduzido e tem sido desenvolvido no Brasil, que integra a Rede Internacional do Index para a Inclusão. Trata-se de um instrumento prático capaz de promover reflexões/ações sobre a construção de culturas, o desenvolvimento de políticas e a orquestração de práticas de inclusão em Educação. Nesse sentido, o instrumento tem potencial para ser desenvolvido em diversos contextos educacionais. Os resultados das pesquisas que o utilizaram, seja como suporte prático ou teórico, ressaltam o potencial reflexivo e formativo do material que contribui para um processo de auto revisão de culturas, políticas e práticas de inclusão em educação.

Palavras Chave: Inclusão em Educação. Exclusão em Educação. Index para Inclusão.

\begin{abstract}
The present article aims at reporting research experiences about the use of the Index for Inclusion in the Brazilian context and its contribution for the studies about the processes of inclusion and exclusion in education. Firstly, we present the instrument and its objectives. We then share the research experiences that involve its use in Brazil. Since its construction and publication in England by Booth; Ainscow (2000) the Index was translated and it has been developed in Brazil, which integrates the Index for Inclusion Network (IfIN). It is a practical tool capable of promoting reflections/actions about the building of cultures, the development of policies and the orchestration of practices of inclusion in education. In this sense, the instrument has potential to be developed in several educational contexts. The results of researches that have used it either as a practical support or a theoretical one highlight its reflective and formative potential which contributes for a self revision process of cultures, policies and practices of inclusion in education.
\end{abstract}

Keywords: Inclusion in Education. Exclusion in Education. Index for Inclusion.

Artigo recebido em 14 de Outubro de 2017 e aprovado em 25 de Abril de 2018.

${ }^{1}$ Departamento de Fundamentos da Educação, Universidade Federal do Rio de Janeiro. E-mail: monicapes@ globo.com.

${ }^{2}$ Mestra em Educação pelo Programa de Pós Graduação em Educação da Universidade Federal do Rio de Janeiro (PPGE/UFRJ), graduada em Pedagogia pela Universidade Federal do Rio de Janeiro (UFRJ). E-mail: manoellasenna@hotmail.com.

${ }^{3}$ Doutoranda em Educação pelo Programa de Pós-Graduação em Educação da Universidade Federal do Rio de Janeiro (PPGE/UFRJ). Mestre em Interdisciplinar Linguística Aplicada pela Universidade Federal do Rio de Janeiro (UFRJ). Graduada em Português-Francês pela Universidade Federal do Rio de Janeiro (UFRJ). Graduada em Português-Inglês pela Universidade Federal do Rio de Janeiro (UFRJ). E-mail: pintoreginamc@ gmail.com.

${ }^{4}$ Mestranda em Educação pelo Programa de Pós-Graduação em Educação da Universidade Federal do Rio de Janeiro (PPGE/UFRJ). Graduada em Licenciatura em Matemática pela Universidade Federal do Rio de Janeiro (UFRJ). E-mail: carol.barreiros.lima@ gmail.com. 


\section{Introdução}

O presente artigo tem por objetivo principal relatar experiências de pesquisas sobre processos de inclusão/exclusão em Educação, edificando um panorama acerca do uso do Index para Inclusão - construído e publicado na Inglaterra por Booth; Ainscow (2000, 2002, 2011) - no contexto brasileiro, após sua tradução por Santos em 2002 e 2011. Cabe ressaltar que o presente panorama não tem por pretensão expor com toda a riqueza de detalhes o trabalho que vem sendo desenvolvido com o Index, tendo em vista que essa apresentação/discussão não se findaria em um único artigo.

O Index para Inclusão tem sido utilizado no Brasil há 17 anos, desde sua primeira tradução realizada pela referida autora brasileira, tanto no campo da pesquisa educacional quanto em outros contextos das práxis universitária e escolar, o que nos evidencia uma demanda de trabalhos e pesquisas significante e inexequível de resumirmos com a tamanha fidedignidade que merecem, em um único espaço.

Além disso, trata-se de um documento riquíssimo que possibilita reflexões acerca da construção de culturas, do desenvolvimento de políticas e da orquestração de práticas de inclusão em educação em instituições de ensino (ou em grupos/equipes, por exemplo, que estão em busca do movimento de (re) visão de seus valores, intenções e ações). O Index, portanto, é um conjunto de materiais, como define Booth; Ainscow (2011) com a potencialidade de apoiar um processo de auto revisão das escolas em direção à ampliação da aprendizagem e da participação dos sujeitos nela inseridos.

Vale ressaltar, como aponta Santos et al. (2014), que nas três versões publicadas do Index, embora tenham sido acrescentadas seções e indicadores para reflexão/ação acerca dos processos de inclusão e exclusão em Educação, a ideia de inclusão como processo aparece fortemente associada a um desenvolvimento do Index de tomada de decisões e ações compartilhadas. Sendo assim, os autores propõem, com o documento, um recurso ao desenvolvimento das escolas em um processo investigativo-ativo, não meramente uma aplicação e uma avaliação das escolas quanto ao seu caráter inclusivo/excludente.

Cumpre assinalar, ainda, que inclusão no referido instrumento é concebida como "processo incessante voltado para o envolvimento de indivíduos, a criação de sistemas e ambientações participativos e a promoção de valores inclusivos" (BOOTH; AINSCOW, 2011). Inclusão em Educação, portanto, envolve colocar valores em ação de modo a minimizar exclusões e/ou barreiras à aprendizagem e à participação de todo e qualquer indivíduo, valorizando-o diante da diversidade. Segundo Ainscow (2009, p.11), “inclusão 
começa a partir da crença de que a educação é um direito humano básico e o fundamento para uma sociedade mais justa".

Sendo o processo de inclusão visto como a participação e aprendizagem plena de toda e qualquer pessoa, no mundo, Senna (2017) reforça que o princípio da inclusão só existe (e se consiste) em relação ao princípio da exclusão. A partir dessa visão, compreendemos, dessa forma, inclusão e exclusão como processos dialéticos e complexos, que se complementam e só existem em função do outro, sendo, portanto, processos indissociáveis.

\section{Index para Inclusão}

A estrutura do Index é composta por uma parte teórica/conceitual que, além de explicitar o conceito de Inclusão, propõe valores a serem desenvolvidos nas escolas, e por uma parte prática dividida em três importantes dimensões: a construção de culturas, o desenvolvimento de políticas e a orquestração de práticas de inclusão em Educação. A dimensão de culturas diz respeito aos valores e crenças compartilhados que orientam as políticas e as práticas. A dimensão das políticas refere-se aos acordos, às intenções e planejamentos (ditos ou não, escritos ou não) que encorajam e permeiam as ações. A dimensão das práticas, por sua vez, dialoga com as próprias ações em prol da minimização de barreiras à aprendizagem e à participação.

As dimensões estão sempre em diálogo e perpassam umas às outras. Por mais que o material esteja dividido nessas três seções, em cada uma, tanto culturas, políticas e práticas podem ser percebidas, visto que a relação que elas estabelecem entre si é dialética (LUCKÁCS, 2003) e complexa (MORIN, 2011). Santos (2013), acrescentando aos estudos sobre inclusão/exclusão enxerga esse processo dinâmico, complementar e exponencialmente transformador das dimensões por meio da perspectiva omnilética, que nas palavras da autora significa:

[...] um modo de explicar/conceber e ser ao mesmo tempo. Um conceito, portanto, de caráter tanto reflexivo e contemplativo quanto aplicativo às nossas práticas, ao nosso modo de ser. O termo omnilética foi criado por mim e é composto de três elementos morfológicos: o prefixo latino omni (tudo, todo), o radical grego lektus (variedade, diferença linguística, mas aqui enfatizando especialmente a variedade e a diferença) e o sufixo grego ico (concernente a). Resumidamente, omnilética significa uma maneira totalizante de compreender as diferenças como partes de um quadro maior, caracterizado por suas dimensões culturais, políticas e práticas em uma relação ao mesmo tempo complexa e dialética (SANTOS, 2013, p.23).

Cada dimensão, por sua vez, é composta por indicadores e questões. Os indicadores são espécies de objetivos que podem ser utilizados como prioridades a serem desenvolvidas na escola que busca refletir sobre os processos de inclusão/exclusão. Já as questões, elas 
detalham os indicadores definindo-os e estimulando discussões mais complexas. Ao final de cada página com os indicadores e perguntas, existe, ainda, um espaço para que sejam acrescentadas novas perguntas e/ou para que questões sejam retiradas e modificadas.

Dessa forma, diante da gama de possibilidades oferecidas pelo Index para Inclusão, o mesmo tem sido desenvolvido em diferentes instâncias da Educação, e de diferentes maneiras. No campo da pesquisa em Educação, por exemplo, no contexto brasileiro, o Index tem sido desenvolvido em escolas envolvendo sujeitos dos grupos de professores, alunos e gestores, assim como em instâncias de gestão, e na administração pública, por exemplo.

O que o torna capaz de abarcar esses diferentes contextos e oferecer subsídios para um trabalho consistente é justamente sua multiplicidade de possibilidades de utilização e, ainda, sua essência transformadora e geradora de reflexão-ação. O Index não tem por objetivo ser um material amarrado que deve ser seguido, mas pretende promover discussões que, inclusive, possam modificar seus próprios indicadores e questões. Tem, portanto, um caráter de construção coletiva, tendo em vista que ele se propõe a ser adaptado de acordo com o contexto em que é utilizado.

Vale sinalizar, ainda, conforme Senna (2017, p. 73):

\begin{abstract}
Tendo em vista que o Index é composto por aspectos teóricos (concepção de inclusão em educação, conceitos e valores que perpassam esse processo) e aspectos práticos (do próprio agir a partir das reflexões), consideramos o mesmo como um instrumento de cunho práxico. [...] A associação do Index para Inclusão como um instrumento práxico, desse modo, dá-se pelo fato de que o mesmo, se desenvolvido tendo em vista sua complexidade e totalidade, permite a modificação constante da teoria por meio da experiência prática, por sua vez modificada pela teoria, numa relação dialética e complexa. Essa práxis constituída e constituinte do Index proporciona aos sujeitos - individual e coletivamente - um olhar atento aos processos de construção de culturas, de desenvolvimento de políticas e de orquestração de práticas em prol ou não da inclusão em educação, considerando as relações existentes entre essas dimensões (culturas, políticas e práticas).
\end{abstract}

No Brasil, o trabalho com o Index seja com seu desenvolvimento, seja com seu referencial teórico-prático, tem sido liderado pelo Laboratório de Pesquisas, Estudos e Apoio à Participação e à Diversidade em Educação (LaPEADE), pertencente à Faculdade de Educação da Universidade Federal do Rio de Janeiro (FE/UFRJ), cuja coordenação tem sido da Prof ${ }^{a}$ Mônica Pereira dos Santos, que traduziu o Index para o português. Nesse sentido, o LaPEADE é pioneiro e tem se tornado referência no próprio país no que tange ao uso desse instrumento.

Considerando a complexidade dos trabalhos realizados com o documento, resumiremos a seguir as principais pesquisas que tiverem como base o Index e, portanto, 
objetivaram momentos de reflexão/ação acerca dos processos de inclusão e exclusão em Educação.

\section{0 uso do instrumento: refletindo sobre inclusão e exclusão em educação}

Apresentaremos nesta seção um breve panorama das pesquisas que envolveram o uso do Index para Inclusão, a fim de relatar experiências de desenvolvimento de reflexões e ações acerca dos processos de inclusão e exclusão em Educação. No que tange aos estudos relacionados a tais processos, esse panorama se faz essencial para que o campo não apenas conheça as possibilidades de trabalho com o Index para Inclusão, como também perceba o potencial do mesmo diante do desenvolvimento de culturas, políticas e práticas de inclusão em Educação.

Entre 2004 e 2007, o LaPEADE desenvolveu a pesquisa intitulada "Ressignificando a Formação de Professores para uma educação Inclusiva" com o objetivo geral de contribuir para a ressignificação da formação de professores da FE/UFRJ para o desenvolvimento de culturas, políticas e práticas de inclusão. Tal pesquisa, de metodologia qualitativa, buscou, por meio de questionários e análise documental, conhecer os sentidos e significados atribuídos pelos alunos da Faculdade de Educação à inclusão e à formação para inclusão (LaPEADE, 2007). Toda a pesquisa foi baseada nos conceitos de culturas, políticas e práticas de inclusão em Educação, proposto pelo Index, que foi utilizado principalmente em torno do seu marco enquanto referencial teórico-analítico, que esteve presente na coleta e na análise dos dados.

Os resultados dessa pesquisa mostraram que a Faculdade de Educação, que pelo menos em teoria, deveria ser modelo de formação e desenvolvimento de culturas, políticas e práticas de inclusão, encontrava-se aquém das expectativas dos estudantes. Entre outros aspectos, verificamos que ela necessitava de rever suas práticas para minimizar a distância entre sua administração e seus estudantes, de modo a potencializar a participação e a aprendizagem de todos. A título de exemplo, eram comuns queixas que se referiam ao mau atendimento e à falta de informações e de comunicação. Importante mencionar que esta pesquisa foi apresentada a toda a Faculdade, no intuito de sensibilizar os gestores, professores e técnicos em direção a uma perspectiva de aprimoramento destes aspectos. Esta mesma pesquisa serviu de base para a primeira pesquisa internacional, que relataremos a seguir, e na qual tentamos replicar parte dos questionamentos da pesquisa feita na Faculdade de Educação, tendo em vista ver se os mesmos problemas se repetiam nas universidades internacionais participantes do projeto. 
Assim, a primeira pesquisa internacional, intitulada de "Culturas, Políticas e Práticas de Inclusão em Universidades: um foco na formação inicial de professores: Brasil, Cabo Verde, Córdoba e Sevilha" (2007-2010) tiveram por objetivo principal descrever e discutir o panorama dos processos de inclusão/exclusão em universidades enquanto instituições formadoras de futuros educadores no tocante às suas culturas, políticas e práticas em âmbito nacional e internacional, a partir da promulgação da Declaração Mundial sobre Educação Superior (1998), nos países supracitados. A pesquisa, de metodologia qualitativa do tipo comparativa, utilizou o Index também por meio do seu marco conceitual de culturas, políticas e práticas tendo em vista que a análise dos dados considerou essas dimensões como macro categorias.

De modo geral, a pesquisa, que teve como respondentes os alunos das universidades dos países citados acima, concluiu que:

[...] em termos dos valores que as políticas inferem, o quadro de inclusão nas universidades pesquisadas foi considerado promissor. Entretanto, quando tomamos como base de análise os variados depoimentos dos futuros professores em formação inicial e as exclusões por que passam na condição de alunos, bem como seus relatos referentes às maneiras como tais políticas são e/ou não são colocadas em prática, percebemos uma contradição visível e contundente nas realidades investigadas (LaPEADE, 2010, p.1).

Tal conclusão motivou a continuação e a expansão da pesquisa para outro olhar, no caso dos professores formadores dos futuros professores. Sendo assim, o LaPEADE realizou entre 2010 e 2014 o estudo intitulado de "Culturas, Políticas e Práticas de Inclusão em Educação Superior: As Vozes dos Formadores de Professores" cujo objetivo geral foi levantar, descrever e discutir o panorama dos processos de inclusão/exclusão nas universidades de Córdoba, Sevilha, Cabo Verde e Brasil no tocante à construção de culturas, ao desenvolvimento de políticas e à orquestração de práticas, de inclusão e/ou exclusão tendo como foco e objeto central de análise os professores das mesmas. A segunda pesquisa internacional, portanto, seguindo os passos da primeira, utilizou metodologia qualitativa do tipo comparativa (SCHNEIDER; SCHMITT, 1998) tendo como referencial teórico as dimensões do Index para Inclusão.

Como diferencial da primeira pesquisa internacional, essa teve os conceitos do Index utilizados na parte metodológica não apenas na análise dos dados, mas principalmente na composição do instrumento de coleta de dados. O questionário, direcionado aos professores formadores de professores das referidas universidades foi pensado em termos das dimensões culturas, políticas e práticas de inclusão em Educação, ou seja, foi dividido em três seções correspondentes às dimensões, tendo algumas perguntas inspiradas no Index para Inclusão. 
De acordo com o panorama aqui exposto, as três pesquisas citadas utilizaram o Index como um instrumento referencial de coleta e análise de dados - em que pese esse modo de utilizar do Index ainda não corresponder ao objetivo geral do mesmo como propõem seus autores e reafirma Santos et al. (2014) já que se trata de desenvolvê-lo nas escolas e outras instituições tendo em vista suas potencialidades de auto revisão. Entretanto, tal fato não descaracteriza sua importância, mas reforça sua relevância no campo da pesquisa educacional, visto que tem um cunho teórico e metodológico promissor em termos de pesquisa.

Acerca do uso do Index, Santos et al. (2014, p. 492) nos alertam veementemente em seu artigo:

\begin{abstract}
Se, no entanto, o Index for utilizado como um instrumento que simplesmente "se aplica" a dado contexto, seu potencial de promover a participação fica perdido. A ideia do Index é a de que ele seja desenvolvido em um processo na escola, e não aplicado como um instrumento de avaliação. Isto é o que lhe dá um caráter emancipatório e político pertinente, portanto, ao ideário da inclusão, posto que desencadeia nas instituições um processo dialógico de auto revisão com a colaboração (mas nunca com os ditames) dos pesquisadores como coautores neste processo, e nunca como direcionadores do processo.
\end{abstract}

Como já aponta Santos et al. (2014) acerca do Index, o mesmo não tem por intenção ser uma checagem de inclusão que busca identificar se uma escola é inclusiva ou menos inclusiva, como se referiram outros autores sobre seu uso (CROCHICK et al., 2011). Tal concepção, inclusive, não condiz com a ideia de inclusão tal qual como defendemos e, ainda, contradiz os autores do Index (BOOTH; AINSCOW, 2000, 2002, 2011) que em suas três versões, conforme estudado por Santos et al. (2014, p. 488), trazem:

[...] ideia de processo na medida em que os textos aludem ao conceito de desenvolvimento da escola e argumenta que inclusão não constitui um estado final ao qual se chegar, mas sempre um ideal a se buscar. Esta mesma noção de desenvolvimento da escola, por sua vez, deixa implícito nestes trechos (mas bastante explícito em outros trechos das três versões do Index, aqui não citados) a importância de se ver o Index como um processo investigativo por meio e ao longo do qual reflexões-ações sobre a realidade escolar são levadas a cabo. Já a ideia de participação fica clara na medida em que as três versões conclamam o leitor, consistentemente, a compreender a inclusão em sua relação com o conceito de exclusão e como ação perene, infindável, de combate à mesma por meio do desenvolvimento de processos investigativo-ativos que levam a tomadas compartilhadas de decisões e ações. Este mesmo compartilhamento é o que fundamenta a participação: ninguém faz inclusão sozinha, nem por decreto.

Diante do exposto por Santos (2014) e pelos autores do Index, acerca do seu uso, podemos inferir que esse instrumento tem o potencial de ser desenvolvido, construído coletivamente entre os sujeitos das escolas. Nesse sentido, o uso do Index para Inclusão, pensando em seu desenvolvimento como um todo, iniciou-se com a pesquisa "Transtornos Globais do Desenvolvimento como desencadeadores de possíveis soluções para os 
Transtornos Globais da Educação”, em 2010, numa escola pública estadual. De acordo com Lago (2014, p. 13-14), essa pesquisa teve como "objetivo central elaborar os indicadores de Inclusão de uma escola por meio do desenvolvimento do 'Index para Inclusão'”. Sua metodologia foi qualitativa do tipo pesquisa-ação (BARBIER, 1985).

Nesse sentido, a originalidade dessa pesquisa, se apresenta no argumento de Lago (2014, p. 20) - um dos frutos dessa pesquisa foi a sua tese de doutorado - na qual a autora defende que trabalhou o Index como:

[...] instrumento teórico-metodológico por meio de seu desenvolvimento em uma escola. Ou seja, não se trata somente de analisar o material enquanto uma proposta teórica, mas de refletir e teorizar sobre a experiência vivida no processo de seu desenvolvimento na prática escolar cotidiana.

Desse modo, a pesquisa iniciou-se com a fase da formação de um grupo coordenador ${ }^{5}$. Segundo Lago (2014), durante três reuniões com representantes de professores, alunos, coordenadores, funcionários e pais a equipe explicou a proposta do Index com objetivo de convidá-los a participar desse processo, tendo em vista que a adesão deveria ser espontânea. Apesar das dificuldades com relação aos encontros desses sujeitos, e à comunicação da escola para a efetiva presença deles, o primeiro grupo foi formado por uma coordenadora pedagógica, uma coordenadora de turno, cinco alunos e quatro professores. Ao longo da pesquisa mais duas professoras aderiram ao grupo e a participação dos alunos foi variada. Os encontros foram estipulados em um calendário e aconteceram sistematicamente durante o primeiro ano da pesquisa. Nesses encontros foram trabalhados alguns indicadores do Index como disparadores de reflexão-ação.

Além dos encontros, a equipe pesquisadora estabeleceu novas estratégias ao longo da pesquisa, tendo em vista alguns percalços da mesma, dentre eles: mudança de gestão, pouca adesão da gestão no processo da pesquisa, pouca comunicação da escola com relação aos encontros com os pesquisadores e, ainda, greve dos professores estaduais. Tais fatos desestabilizaram o trabalho do grupo coordenador e, assim, foi preciso pensar em outra configuração da pesquisa, como por exemplo, o ciclo de palestras para os alunos com temas de discussão demandados por eles, e o acompanhamento de um projeto coordenador por uma das professoras pertencentes ao grupo coordenador.

Assim sendo, a coleta de dados contou com a técnica de observação participante (que geraram relatórios de campo), o uso de questionários, e a análise documental. O questionário

\footnotetext{
5 Para o Index, o seu e desenvolvimento inclui como passo inicial a organização coletiva de um Grupo Coordenador, cuja tarefa será a de liderar o processo e representar a comunidade institucional (em seus variados segmentos) durante o mesmo.
} 
utilizado foi um dos propostos pelo Index. Isso porque ao final das seções, o instrumento traz como sugestões alguns anexos, como, por exemplo, este questionário de questões mistas (abertas e fechadas) a respeito de como o aluno se vê dentro da escola, em termos de participação e aprendizagem, com indicadores relacionados às culturas, políticas e práticas de inclusão na escola.

Durante os encontros com o grupo coordenador, os indicadores do Index foram trabalhados como disparadores de temas a serem discutidos na percepção de alunos, professores e coordenadores. Dessa forma, o Index foi sendo desenvolvido tendo em vista seu caráter de auto revisão de culturas, políticas e práticas de inclusão em educação. Um dos principais temas discutidos foi a dificuldade de comunicação na escola, apontada em unanimidade por todos os sujeitos participantes da pesquisa, como vemos abaixo:

\begin{abstract}
Carlos (aluno) diz que o problema maior é a comunicação, e não a avaliação que foi diagnosticada na última reunião, pois, em relação à avaliação, eles se entendem com os professores. Ele diz que a comunicação é tão ruim que nem os murais os alunos leem e que os alunos do grêmio já tentaram fazer um jornal, mas não havia verba para impressão. Ele também reclama que a escola tem todo um equipamento para fazer uma rádio, mas que ele não entende por que essa rádio não acontece (Relatório 7.1, p. 4, 21 de Jun. 2010).

Adriana (coordenadora pedagógica) fala sobre a necessidade de haver um quadro de avisos organizado com informações precisas, já que "cada um dá uma informação diferente". Silvia (diretora) fala sobre a necessidade de os murais serem fechados porque as pessoas tiram os avisos dos quadros (Relatório 8, p. 2, 28 de Jun. 2010). Silvia (diretora) disse que nós estávamos ajudando muito e que já sabia dos problemas de comunicação da escola e que por isso tinha feito um caderno com uma circular para cada um dos professores fazendo cada um deles assinar ao receber a circular (Relatório 10, p. 1, 12 de Jul. 2010).
\end{abstract}

Considerando que esse processo se desenvolveu ao longo de quatro anos, inúmeras mudanças ocorreram na escola e, principalmente com a pesquisa. Além dos percalços pontuados acima, foi notável que a falta de engajamento da gestão da escola com o projeto (principalmente dos diretores) foi um fator que contribuiu para a dispersão do grupo coordenador e, assim, consequentemente, para o pouco desenvolvimento do instrumento de reflexão-ação com toda a potencialidade que o mesmo proporciona. A não participação do grupo dos pais e dos funcionários não nos permitiu também contemplar a participação democrática pretendida no início da pesquisa. Segundo relatórios de campo, essa não participação desses segmentos demonstra, em parte, um desejo de perpetuação da cultura de hierarquização de saberes e poderes:

Uma professora questiona a participação dos funcionários dizendo que eles tinham outro nível cultural e ela não entendia no que eles poderiam contribuir com a prática dela, já que ela tinha domínio total sobre a turma e o desenvolvimento de sua aula (Relatório 3, p. 2-31 de Mai. 2010). 
Disseram que achavam que este primeiro momento (a reunião do dia 6) deveria ser apenas com professores e não com toda a comunidade escolar. Que eles precisavam ser seduzidos pela nossa proposta, que se eles comprassem a nossa ideia o projeto andaria e eles influenciariam pais e alunos, chamando-os a participar (Relatório 1, p. 5-30 de Abr. 2010).

Paradoxalmente, apesar dos obstáculos encontrados e das mudanças que tiveram que ser realizadas, a pesquisa teve como conclusão que o Index é um instrumento fecundo para auxiliar as escolas nesse processo de revisão, em termos de participação e da construção de estratégias mais inclusivas.

Outra pesquisa que buscou desenvolver o Index em totalidade foi a "Construindo Culturas, Desenvolvendo Políticas e Orquestrando Práticas de Inclusão no Cotidiano Escolar", iniciada em 2012, em uma escola pública municipal, teve como objetivo principal:

[...] proporcionar um exame detalhado das possibilidades de incrementar a aprendizagem e a participação para todos os alunos no âmbito escolar, através do auxílio aos professores, no engajamento no planejamento, na escolha de prioridades necessárias às mudanças, na proposição de inovações e na revisão de progresso de todas as atividades (LaPEADE, 2012, p. 4).

Por solicitação da escola, a equipe do LaPEADE realizou uma pesquisa-ação (THIOLLENT, 1996) com o grupo de professores e coordenadores. Inicialmente, os pesquisadores inseriram-se no contexto das aulas para observarem culturas, políticas e práticas de inclusão/exclusão. Essa observação foi feita por pesquisadores inseridos in lócus com auxílio das gravações de vídeos que, posteriormente, foram minutadas. Cada pesquisador produzia, em cada aula observada, um relatório de campo. Vale ressaltar que ao final de cada aula o pesquisador perguntava ao professor quais os pontos positivos e os pontos negativos da aula realizada.

Após esse período de observação, foi constituído, como sugere Booth; Ainscow (2002), o grupo coordenador - composto por professores e coordenadores. Sendo assim, as gravações foram utilizadas como disparadores de discussão a partir do momento em que eram levadas ao grupo coordenador para análise. Associado aos "casos" apresentados para reflexão, a equipe se deparava com os indicadores do Index de modo a não apenas refletir sobre eles, mas principalmente propor novas ações para minimização de barreiras à aprendizagem e à participação.

Como fruto desse processo de reflexão-ação, a escola solicitou ajuda aos pesquisadores para a construção de um Projeto Político Pedagógico (PPP) da escola, tendo em vista que, apesar de constar em lei (LDBEN - Lei №. 9.394/96), a mesma não possuía um. Sendo assim, por meio do desenvolvimento do Index, a principal produção do grupo 
coordenador foi o seu PPP. Além dos itens necessários de um PPP como valores, missão e visão, a escola construiu suas estratégias, tendo em vista os indicadores do Index, consideradas por ela, naquele momento e contexto, como prioridade de ação. Essas estratégias foram pensadas em termos de culturas (valores, crenças), políticas (objetivos, intenções) e práticas (ações, decisões):

\subsection{2 - Relacionamento interpessoal \\ Culturas:}

Cuidado em apresentar os funcionários da escola;

Acolhimento dos alunos novos;

Acolhimento dos novos funcionários;

Compartilhar missões, ações, dizer o que eu espero do outro;

Conhecer quais são as atribuições de cada um;

Compromisso em conhecer qual é a minha função e o que eu posso fazer;

Incentivar o comprometimento

Políticas:

Acolhimento aos novos funcionários e alunos;

Envolvimento dos responsáveis por meio das reuniões onde serão esclarecidas as ações da escola.

\section{Práticas - Estratégias:}

Apresentação dos novos alunos;

Apresentação dos novos funcionários;

Apresentação da escola para os responsáveis. Usar vídeos da escola - vídeo institucional;

Parceria com o núcleo de artes para montagem do vídeo/filme com os alunos;

Solicitação ao núcleo para a oficina de informática. Criar uma propaganda na sala de aula para os interessados;

Construir uma proposta para os professores sobre o uso das novas tecnologias na educação. Acionar o Núcleo de Formação para parceria nos projetos de atualização nas novas tecnologias (PPP da escola, 2015, p. 10).

Todo o processo de construção (participativa e ativa) desse PPP foi baseado nos indicadores do Index, sendo eles sempre escolhidos, discutidos e escritos pelo grupo coordenador, tendo em vista as prioridades da escola. A pesquisa ainda não apresenta relatório final. Entretanto, por ora, é possível apontar que o Index além de propositor de revisões nessa pesquisa, tem sido base de um documento importante da escola que organiza intenções perpassadas por valores e que se finalizam em práticas que podem ser ou não na orientação da inclusão em Educação.

Fruto de uma parceria entre a UFRJ e a Escola de Contas e Gestão (ECG) no Tribunal de Contas do Estado do Rio de Janeiro (TCE-RJ), no ano de 2013 foi iniciada uma pesquisa cujo objetivo foi ajudar a instituição a promover, em base contínua, um processo de autorreflexão dos valores da Instituição e, a partir disso, propor ações que pudessem melhorar as culturas, políticas e práticas institucionais de inclusão. Tendo como base o Index para Inclusão, o mesmo foi adaptado para o contexto dessa Escola de Governo e para o 
desenvolvimento do trabalho, foi criado um grupo representativo dos diferentes setores da Escola, denominado Grupo Coordenador, que participou dos quinze encontros realizados.

A adaptação do Index para esse contexto fez-se necessária, já que esse instrumento estava sendo utilizado, pela primeira vez, para um público constituído por adultos, o que determinou o caráter inovador dessa pesquisa. Assim, termos como 'adolescentes/crianças', ou 'pais/responsáveis', foram substituídos por 'servidores, servidoras ou participantes da comunidade', por exemplo.

Adotou-se a pesquisa-ação crítico-colaborativa como metodologia de pesquisa e a observação participante, o registro em cadernos de campo, fotografias e gravações em áudio foram os instrumentos utilizados para a coleta dos dados. Durante o processo de auto revisão, desencadeado pelo Index, que acontecia quinzenalmente, a principal 'queixa' da comunidade pesquisada, trazida pelo grupo coordenador, era a de uma forte hierarquização da instituição, que levava a uma valorização desigual entre os servidores da mesma. Com o intuito de refinar o entendimento dessa demanda, na tentativa de atendê-la, foi realizada uma consulta à comunidade, para responder à seguinte questão: “O que podemos fazer para que tod@s e cada um/a se sintam igualmente valorizad@s?"

Os resultados dessa enquete, e a subsequente reflexão sobre a mesma, suscitou por sua vez, a elaboração de um Plano de Ação, a ser implementado na ECG em 2017. A consulta apresentou como propostas: a construção dos valores institucionais, os quais passaram a fazer parte do Plano de Desenvolvimento Institucional (PDI); além disso, foi sugerida a criação da semana/seminário de Inclusão com a presença de grupos de movimentos sociais, de pessoas com deficiências, negros, indígenas, LGBT etc. A pesquisa, conclui que o Index constitui rico material que possibilita o trânsito da instituição de um lugar que reflete pouco ou nada sobre si mesma no que tange à promoção de inclusão, à uma posição de autorreflexão de suas culturas, políticas e práticas.

Para concluir as experiências em pesquisa com o referido instrumento apresentamos a pesquisa "Desenvolvendo o Index para Inclusão na Gerência de Educação da Segunda Coordenadoria Regional de Educação (CRE) da Rede Municipal do Município do Rio de Janeiro". Trata-se de uma pesquisa pioneira com relação ao uso do Index para Inclusão. Isso porque, diferente das outras pesquisas, esta se propôs a desenvolver o Index na e com uma gerência de educação (GED), ou seja, uma equipe de gerentes que faz a mediação entre as políticas advindas da Secretaria Municipal de Educação do Rio de Janeiro e as escolas sob sua 
coordenação (localizadas em sua maioria na Zona Sul, mas com inserção de escolas da Zona Norte e Centro do Rio de Janeiro).

Cabe ressaltar aqui, que inicialmente a GED nos procurou para que pudéssemos desenvolver o Index com as escolas da $2^{\text {a }}$ CRE. Entretanto, ao mostrarmos a complexidade do material, bem como o nível de discussão por ele proposto, a equipe de gestores considerou necessário desenvolver o Index com a própria Gerência e depois ampliar o projeto com as escolas, visto que a Gerência precisava entender esses processos de inclusão/exclusão e refletir-agir para que, nas escolas, o trabalho fosse respaldado.

O objetivo da pesquisa na GED foi instituir uma cultura de auto revisão junto à Equipe da Gerência de Educação da 2a Coordenadoria Regional de Educação do município do Rio de Janeiro, tendo em vista uma orientação inclusiva de gestão, por meio do desenvolvimento do Index para Inclusão.

Nesse sentido, a pesquisa desde o seu início em 2014 desenvolveu o Index da própria GED, considerando suas especificidades. Por não se tratar de uma escola propriamente, todo o Index foi adaptado para o contexto de uma gestão, ou seja, todos os seus indicadores foram modificados para uma melhor leitura, compreensão e identificação da equipe, como por exemplo:

\section{Quadro 1: Adaptação do Index para o Contexto da GED}

\section{Versão Oficial Index (Booth; Ainscow, 2012)}

Dimensão A: Criando culturas inclusivas

A1: Edificando a comunidade

A1.1 Todos são bem vindos.

a) O primeiro contato que as pessoas têm com a escola é acolhedor?

b) Os profissionais, os alunos e as famílias criam um senso de comunidade na escola?

c) A escola é receptiva a todos os pais/responsáveis e outros membros das comunidades locais?

d) A escola é receptiva àqueles que tenham chegado recentemente de outro local no país ou de outro país?

e) Os profissionais, alunos e pais/responsáveis se cumprimentam de forma educada e amistosa?

f) Os profissionais, crianças, pais e gestores esforçam-se por aprender os nomes uns dos outros?

g) O espírito das pessoas se eleva ao visitarem a escola?

\section{Versão Adaptada do Index para a GED}

Dimensão A: Criando culturas inclusivas

A1: Edificando a comunidade

A1.1 Todos são bem vindos.

a) O primeiro contato que as pessoas têm com a GED é acolhedor?

b) Os profissionais criam um senso de comunidade na Gerência?

c) A GED é receptiva a todos das comunidades locais?

d) A GED é receptiva àqueles que tenham chegado recentemente de outro local no país ou de outro país?

e) Os profissionais da GED se cumprimentam de forma educada e amistosa?

f) Os profissionais da GED esforçam-se por aprender os nomes uns dos outros?

g) O espírito das pessoas se eleva ao visitarem a GED?

\section{Fonte: Elaborado pelas autoras}

Essa adaptação foi feita principalmente para que a GED se identificasse com essas questões e melhor pudesse discuti-las. Assim, foram modificadas palavras e frases, retiradas e acrescentadas perguntas pertinentes à especificidade do trabalho dessa Gerência. 
O desenvolvimento do Index aconteceu na GED por meio de encontros quinzenais entre equipe pesquisadora e gerentes. No primeiro momento, foi trabalhado o conceito de Inclusão bem como os valores propostos no Index, de modo a discutir quais seriam os valores coletivos da Gerência. Depois de explicado como funciona o instrumento e qual o seu objetivo, iniciamos a fase com os indicadores. Assim, a cada encontro a equipe pesquisadora selecionava um grupo de indicadores (sempre em sequência para que todos pudessem ser estudados). O grupo de aproximadamente 40 gestores dividia-se em pequenos grupos para leitura minuciosa e escolha dos indicadores e perguntas que dialogavam com as prioridades do grupo naquele momento. A partir dessa escolha, que gerava uma discussão e reflexão entre eles, cada grupo preenchia um plano de ação pensando: como ocorre no momento e o que se pretende a partir de agora.

Após preenchimento dos planos, os grupos apresentavam suas propostas uns para os outros e elas eram corroboradas por todos ou não. Dessa discussão maior, levantavam-se, então, as prioridades. Sempre, antes de iniciar o encontro retomávamos a leitura das propostas do encontro anterior, tendo em vista novas considerações e reflexões, já que uma semana havia passado e outras formas de enxergar aquele indicador poderiam aparecer. Esses planos de ação foram compilados em um único documento que chamamos de "Indicadores do Index para Inclusão da GED/2a CRE". Vale ressaltar que esses planos foram uma construção da própria equipe e refletiam os temas emergenciais de serem aprimorados no trabalho, conforme exemplo abaixo de uma questão discutida:

\footnotetext{
A1 Edificando a Comunidade

A1. 1. Todos são bem vindos?

F) O espírito das pessoas se eleva ao visitarem a GED?

Como ocorre?

Não havendo espaço físico para desdobrar a diversidade de ações, causa mal-estar não só à equipe como às pessoas que buscam esclarecimentos.

Propostas:

Que haja uma reformulação do espaço físico no nível da Coordenadoria, considerando a importância da inclusão no âmbito social.
}

Destacamos que entre as discussões dos indicadores outras demandas específicas da GED viraram pauta dos encontros, como, por exemplo, uma conversa mais especifica sobre gênero e diversidade sexual na escola. Para atender essa demanda, convidamos um pesquisador da área para esclarecer dúvidas e propor um debate. Esses momentos foram enriquecedores e colaboraram com o desenvolvimento da pesquisa.

Nas discussões preliminares com o Index, a Gerência percebeu a importância de se ter um documento que pudesse revelar os valores e a missão da GED/2 ${ }^{\mathrm{a}} \mathrm{CRE}$, tendo em vista que ela se diferenciava das demais Gerências (ao todo são 11 CREs) e pretendia demonstrar essa 
diferença e autonomia. A GED/2 ${ }^{\mathrm{a}} \mathrm{CRE}$ entendeu como necessário pensar em um PPP da própria Gerência. O objetivo dessa proposta foi construir um PPP diante da discussão de valores do Index e pensar as estratégias tendo como base as discussões dos indicadores, já realizada pela equipe, diante das dimensões de culturas, políticas e práticas de inclusão em Educação.

Houve momentos na pesquisa em que foi preciso parar e discutir a própria dinâmica e sua importância para a GED. Isso porque alguns membros apontaram que não era mais de comum acordo que o desenvolvimento do Index estava tendo resultados positivos. Sendo assim, em um encontro relembramos o motivo da presença dos pesquisadores lá, bem como os desdobramentos que aconteceram desde então (ex.: o curso de gestão participativa, que foi planejando como um desdobramento das discussões; o encontro sobre gênero e sexualidades (demanda do grupo), as avaliações do trabalho da GED no meio do ano e ao final do ano, pela própria equipe, a fim de identificar itens a serem aprimorados, presença da GED nos encontros com os pesquisadores e mudança no espaço físico e na estrutura das reuniões da Gerência, tendo em vista uma orientação de inclusão).

Mostramos para a GED, por meio das próprias transcrições (visto que todos os encontros são gravados em vídeo e áudio), falas em que os participantes da pesquisa demonstram as crenças e as descrenças da pesquisa a fim de refletirmos sobre a sua continuação:

\footnotetext{
[Referindo-se a pergunta da pesquisadora se quando a equipe de pesquisadores sai da GED, existe ou não continuação das discussões do Index]

EM: Não discute em si diretamente. Mas, na prática, a gente realmente tá ali se avaliando e colocando assim pra Morgana as coisas. Eu acho. É uma coisa dinâmica. A gente não fica na teoria. Não. Na teoria não...

M: (cortando) Então você acha que a discussão, o que trabalha aqui não se perde, permanece no dia a dia da GED?

EM: Toda hora (LaPEADE, Bloco de Anexos, p.164).

D: Isso foi o que eu achei mais bacana da outra reunião. Porque o que aconteceu: as pessoas produzem questões, elas pensam a respeito de um determinado assunto e elas escrevem. Então, isso é bacana pra gente estar conhecendo (LaPEADE, Bloco de Anexos, p.242).

F: Já existiu momento que a gente teve formação.

MG: Mas o que ela tá colocando é o seguinte: como que a gente não vê esse momento com o LaPEADE, como um momento de formação.

E: É porque a gente fica focado no pedagógico, ligado a alfabetização.

MG: acho que é o conceito que ela tá trazendo.

F: A gente sempre acha que é uma coisa mais teórica (LaPEADE, Bloco de Anexo, p. 185).
}

Após esse momento de tomada de consciência sobre o próprio encaminhamento da pesquisa, comum em pesquisa-ação, tendo em vista seu caráter flexível, transformador e reflexivo-ativo, a equipe gestora percebeu que muitas coisas já haviam sido modificadas no trabalho da equipe, consideradas positivas. Além disso, ainda tinham o desejo de permanecer 
com o desenvolvimento do Index, julgando ser necessário para a minimização de barreiras à participação e à aprendizagem no próprio relacionamento da Gerência.

O desenvolvimento do Index no contexto da Gerência de Educação durou cerca de dois anos em um processo de reflexão e ação contínuo, e fortemente atrelado ao caráter formativo de seus participantes. As principais categorias de reflexão/ação que surgiram diante do contato com o Index foram: acolhimento; organização; conhecimentos; relação GED e comunidade externa; colaboração; diversidade de opiniões; e participação. Essas categorias, durante do trabalho com os planos de ação, tornaram-se essenciais para a GED (re)visitar suas culturas, políticas e práticas de gestão e de inclusão em Educação.

Segundo Senna (2017), como resultados, a pesquisa mostrou que o desenvolvimento do Index na GED proporcionou à equipe: um processo de auto revisão de culturas, políticas e práticas de gestão e de inclusão em educação; um olhar mais atencioso e de acolhimento às diferenças; construção de um PPP próprio da GED; mudanças nas equipes de trabalho e nos planejamentos tendo em vista acompanhamento das escolas; além de momento de formação continuada em equipe.

É possível notar que a quantidade de pesquisas envolvendo esse material de auto revisão não é pequena. Considerando que o Index teve sua primeira publicação em 2002 no Brasil, pode-se questionar que poderíamos ter avançado mais em termos de pesquisa. Entretanto, como já definido anteriormente, o Index não se trata de um instrumento aplicável. Ele precisa ser desenvolvido e esse desenvolvimento não pode ser em tempo curto, já que a reflexão, seu principal objetivo, não é estanque. Um processo de auto revisão demanda tempo para reflexão-ação-reflexão e, ainda, precisa ser coletivo, participativo e democrático. $\mathrm{Ou}$ seja, não deve ser imposto pelos pesquisadores, mas demandado pelos contextos de cada instituição educacional.

\section{Conclusão}

Pretendemos com o presente artigo realizar um breve panorama acerca do uso do Index para Inclusão e sua importância para a reflexão sobre os processos de inclusão e exclusão em Educação, por meio de relatos de experiências de pesquisa em que o instrumento foi utilizado seja como referencial teórico seja como referencial metodológico. Ressaltamos que, com a finalidade de organizar e fortalecer os trabalhos com esse material de auto revisão, os países que utilizam o Index para Inclusão constituíram uma Rede Internacional do Index 
para Inclusão6. Essa rede tem por objetivo conectar ideias sobre o uso desse instrumento, compartilhando experiências que envolvem escolas e outras instituições de educação. É uma forma de não apenas divulgar o Index para Inclusão como também criar uma comunidade que se ajude, compartilhando valores inclusivos.

Além do seu uso com liderança do LaPEADE, há 14 anos, outros estados brasileiros (São Paulo, Alagoas) demostraram interesse em participar da Rede Internacional do Index para Inclusão.

Consideramos de extrema importância que o Index seja desenvolvido em outros Estados do Brasil. Se queremos uma Educação sem barreiras à aprendizagem e à participação, mais democrática e desejada por seus professores e alunos, temos muito o que discutir e, principalmente, agir e esse documento tem a capacidade de oferecer profundas reflexões e mudanças, se trabalhado com a seriedade que merece, pois temos em mãos um arcabouço de materiais que convidam ao diálogo e propõem iniciativas compartilhadas em prol da inclusão.

No momento, temos entendido a importância de investirmos em pesquisas com as gestões. Isso porque no Brasil, nossa rede pública de escolas não apresenta autonomia no que tange a culturas, políticas e práticas. Principalmente por questões políticas, as escolas não têm tido espaço para se colocarem e agirem em determinadas situações, pois devem explicações às suas secretarias que acabam, por sua vez, inibindo determinadas ações. Estamos inseridos em uma cultura não democrática na qual os professores não planejam suas avaliações, sendo as mesmas definidas por uma secretaria que não respeita a diversidade de escolas e sujeitos nelas inseridos. Nesse sentido, avançar as discussões com o Index em nível de gestão tem nos dado esperança de repensar sobre essa cultura não democrática e não participativa da Educação.

Diante do objetivo proposto por este artigo, consideramos fundamental compartilhar as experiências de pesquisa relacionadas ao uso do instrumento Index para Inclusão. Por se tratar de um instrumento com alto potencial para reflexão e ação sobre culturas, políticas e práticas de inclusão, o conhecimento sobre seu uso e possibilidades amplia o campo dos estudos acerca dos processos de inclusão e exclusão em Educação. Desse modo, esperamos com este trabalho, para além da divulgação do uso do instrumento, demonstrar como o mesmo tem sido adaptado e desenvolvido no contexto educacional brasileiro, enriquecendo a consolidada Rede Internacional do Index para Inclusão.

\footnotetext{
${ }^{6}$ Disponível em: http://www.indexforinclusion.org/index.php
} 


\section{REFERÊNCIAS}

BARBIER, R. A pesquisa-ação na instituição educativa. Rio de Janeiro: Jorge Zahar, 1985.

BOOTH, T; AINSCOW, M. Index para Inclusão: desenvolvendo a aprendizagem e a participação na escola. Tradução: Mônica Pereira dos Santos. 3. ed. LaPEADE, Rio de Janeiro, 2011.

LAGO, Mara. Index para a Inclusão: uma possibilidade de intervenção institucional. 2014. Tese (Doutorado em Educação). Faculdade de Educação, Universidade Federal do Rio de Janeiro, Rio de Janeiro, RJ, 2014.

LaPEADE. Bloco de Anexos. Desenvolvendo o Index para Inclusão na Gerência de Educação da Segunda Coordenadoria Regional de Educação da Rede Municipal da Cidade do Rio de Janeiro, 2014.

LaPEADE. Projeto de Pesquisa: Culturas, Políticas e Práticas de Inclusão em Educação Superior: As Vozes dos Formadores. 2010. Disponível em:

http://www.lapeade.com.br/publicacoes/pesquisas/Projeto_UFRJ_UCV_UCO.pdf Acesso em: 10 de ago. 2017.

LAPEADE. Projeto de Pesquisa: Construindo Culturas, Desenvolvendo Políticas e Orquestrando Práticas de Inclusão no Cotidiano Escolar. 2012. Disponível em: http://www.lapeade.com.br/publicacoes/pesquisas/PROJETO\%20CICERO\%20FINAL.pdf Acesso em: 10 de ago. 2017.

LaPEADE. Relatório de Pesquisa: Ressignificando a Formação de Professores para uma Educação Inclusiva. 2007. Disponível em:

http://www.lapeade.com.br/publicacoes/pesquisas/relatorio_final_04-07.pdf Acesso em: 13 de ago. 2017.

LaPEADE. Relatório de Pesquisa: Culturas, Políticas e Práticas de Inclusão em universidades: um foco na formação inicial de professore. 2010. Disponível em: http://www.lapeade.com.br/publicacoes/pesquisas/Relatorio_final_09_04_10.pdf Acesso em: 15 de ago. 2017

LaPEADE. Relatório de Pesquisa: Transtornos Globais do Desenvolvimento como Desencadeadores de Possíveis Soluções para os Transtornos Globais da Educação. 2014.

Disponível em:

http://www.lapeade.com.br/publicacoes/pesquisas/RELAT\%C3\%93RIO\%20FINAL\%20PRO JETO\%20JANNUZZI.pdf Acesso em: 15 de Ago. 2017.

LUKÁCS, G. História da Consciência de Classe: estudos sobre a dialética marxista. São Paulo: Martins Fontes, 2003.

MORIN, E. Introdução ao Pensamento Complexo. Porto Alegre: Sulina, 2011. 
SANTOS, M. P dos. Dialogando sobre inclusão em educação: contando casos (e descasos). Curitiba: CRV, 2013.

SANTOS, M. P dos et al. O Index para Inclusão como instrumento de pesquisa: uma análise crítica. Rev. Bras. Ed. Esp., Marília, v. 20, n. 4, p. 485-496, out./dez., 2014. Disponível em: http://dx.doi.org/10.1590/S1413-65382014000400002. Acesso em: 18 de ago. 2017.

SCHNEIDER, S.; SCHIMITT, C. J. O uso do método comparativo nas Ciências Sociais. Cadernos de Sociologia. Porto Alegre, v. 9, p. 49-87, 1998.

SENNA, Manoella. (Re)visitando culturas, políticas e práticas de inclusão em educação no nível da gestão municipal de educação: a $2^{\text {a }}$ CRE em ação. Rio de Janeiro, 2017. Dissertação (Mestrado em Educação). Faculdade de Educação, Universidade Federal do Rio de Janeiro, Rio de Janeiro, 2017.

THIOLLENT, Michel. Metodologia da Pesquisa-Ação. 2. ed. São Paulo: Cortez, 1986. 